Medicine Updates Faculty of medicine

October 2021,volume 7, issue 7 https://muj.journals.ekb.egdean@med.psu.edu.eg vice_dean_postgraduate@med.psu.edu.eg DOI: 10.21608/muj.2021.90507.1055

\title{
" Clinical Profile of Patients with Hyperthyroidism in Zagazig University Hospitals "
}

\section{Authors}

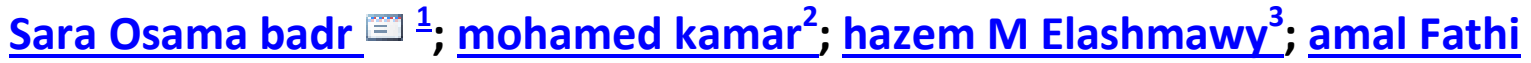
gharib $^{4}$; Ekhlas M Hussein ${ }^{5}$

${ }^{1}$ internal medicine department, faculty of medicine, Portsaid University

${ }^{2}$ internal medicine department, faculty of medicine, Zagazig University

${ }^{3}$ Internal medicine department, faculty of medicine, Zagazig University

${ }^{3}$ Internal medicine department, faculty of medicine, Zagazig university

${ }^{4}$ Department of clinical laboratory sciences, college of applied medical sciences

,Taif University, Taif Clinical biochemistry Department, Faculty of Medicine, Zagazig University.

${ }^{5}$ Clinical cardiology Department, Faculty of Medicine, Zagazig University, Zagazig,Egypt

${ }^{5}$ Clinical cardiology Department, Faculty of Medicine, Zagazig University, Zagazig,Egypt 


\begin{abstract}
Background

Hyperthyroidism is a condition that occurs due to over production of thyroid hormones by the thyroid gland . It can be categorized according to thyroid hormone levels into overt and subclinical hyperthyroidism. Also could be classified into, normal (or high) and low thyroid radioactive iodine uptake according to radioiodine uptake. Diagnosis and identification of each category of hyperthyroidism is based on assay of thyroid hormones plus thyroid gland scintigraphy. So, the aim of this study was to evaluate the difference in clinical and biochemical profile between hyperthyroid patients and its relation to thyroid scan imaging, for better management and follow up of hyperthyroid patients. Also to avoid prescribing antithyroid medications to patients with thyroiditis, this could lead to hypothyroidism or other side-effects
\end{abstract}

Materials and methods: This is a prospective cohort study for patients with hyperthyroidism. Patients have been enrolled from Endocrinology Outpatient Clinic at Zagazig University Hospitals in the period from December 2018 to October 2020.

Results: patients were divided into two major groups, overt hyperthyroidism (group 1) and subclinical hyperthyroidism (group 2). All patients of group (1) had abnormal thyroid gland examination but, only $50 \%$ of group (2) patients had showed abnormal gland examination $(\mathrm{p}=<0.001) .83 .3 \%$ of patients of group (1) had high thyroid uptake and $62.5 \%$ of patients of group (2) had high thyroid uptake $(\mathrm{p}=0.108)$. As regard thyroid hormones, there was highly statistical significance between the two groups as regard F. T4( $\mathrm{P}=<0.001)$ and F.T3 $(p=<0.001)$, but no difference in $\operatorname{TSH}(\mathrm{p}=0.223)$.

Conclusion: The thyroid scan had cross linkage with abnormal thyroid clinical and biochemical data, helping in differentiating the causes of overt hyperthyroid and subclinical hyperthyroid dysfunction. 
Keywords: hyperthyroidism; categories; scan.

\section{Introduction:}

Hyperthyroidism is a medical disorder that occurs due to release of abnormal higher levels of thyroid hormones by the thyroid gland to be differentiated from thyrotoxicosis, which is defined as the condition that occurs due to overproduction of thyroid hormone due to any cause and so includes hyperthyroidism ${ }^{[1]}$. Subclinical hyperthyroidism is characterized by depressed levels of serum thyroid stimulating hormone (TSH) with free triiodothyronine (FT3) and free thyroxin (FT4) levels within laboratory reference ranges ${ }^{[1]}$. According to radioiodine uptake two categories can be identified, normal or high thyroid radioactive iodine uptake (thyrotoxicosis with hyperthyroidism or true hyperthyroidism) and low thyroid radioactive iodine uptake (Thyrotoxicosis without hyperthyroidism is caused by extra thyroidal source of thyroid hormone or by a release of preformed thyroid hormones into the circulation ) ${ }^{[2]}$. The above normal levels of thyroid hormones are harmful to many different organ systems. Most of the patients presented with palpitations, fatigue, tremor, anxiety, disturbed sleep, weight loss, heat intolerance, sweating, and polydipsia. Frequent physical findings are tachycardia, tremor of the extremities, and weight loss ${ }^{[3]}$. Diagnosis of thyrotoxicosis is mainly based on assay of thyroid hormone levels, first serum TSH should be estimated because it has the highest sensitivity and specificity in the diagnosis of thyroid disorders. If low, serums free T4 or free T4 index, and free or total T3 concentrations should be assessed to distinguish between subclinical hyperthyroidism and overt hyperthyroidism ${ }^{[4]}$. Thyroid scans and uptakes had important role in discrimination of type of thyrotoxicosis, as well as diffuse and localized over activity ${ }^{[5]}$.

\section{Patient and methods:}

This prospective cohort study was planned to evaluate 48 patients with hyperthyroidism. They were categorized into two groups ,group (1) 24 patients 
with overt hyperthyroidism, and group (2) 24 patients with subclinical hyperthyroidism . Group (1) overt hyperthyroid patients: recently diagnosed or already on antithyroid drugs treatment, whom had supra normal levels of (T4, T3) and low TSH.

Group (2) subclinical hyperthyroid group: patients whom originally subclinical hyperthyroidism or developed subclinical hyperthyroidism during course of treatment of hyperthyroidism, with normal levels of (T4, T3) and low TSH. All were from 18 to 65 years old, both sexes included in the study excluding pregnant and lactating females. All of them must have low suppressed TSH level. They were enrolled from the Outpatient Clinic at Zagazig University Hospitals in the period from December 2018 to October 2020. Clinical and laboratory data were obtained such as age, gender, neck examination, eye examination and routine laboratory investigations .Plus, thyroid function tests and thyroid scan examination. All subjects participated in the study provided written informed consent. The study was approved by the research ethical committee of Zagazig University's Faculty of Medicine.

Testing for TSH, free T3 and free T4: Blood sample collection: $5 \mathrm{ml}$ of peripheral fasting venous blood were taken from each subject under complete aseptic conditions, Each sample left for 30 minutes for spontaneous clotting then centrifuged at $3000 \mathrm{rpm}$ for 5 minutes to obtain serum samples and kept frozen until the time of assay of thyroid function (TSH, FT3 and FT4).

TSH: Human thyroid stimulating hormone ELISA kit, Inteco Diagnostics UK Ltd, 62 Beechwood Road, E8 3DY England. This test is based on the principle of a solid phase enzyme-linked immunosorbent assay. The TSH present in the sample originates a coloured complex. The intensity of the colour formed is directly proportional to the TSH concentration in the sample.

FT3: Human Free Triiodothyronine (F-T3) ELISA kit, Catalog No. E1004. AUTOBIO Diagnostics Co., LTD, Zhengzhou, China. The free T3 present in the 
sample originates a coloured complex. The color intensity is inversely related to the concentration of free $\mathrm{T} 3$ in the test sample.

FT4: Human Free thyroxine (F-T4) ELISA kit, Catalog No. E1005. AUTOBIO Diagnostics Co., LTD, Zhengzhou, China. The free T4 present in the sample originates a coloured complex. The color intensity is inversely related to the concentration of free $\mathrm{T} 4$ in the test sample.

The research was conducted out in conformity with the World Medical Association's Code of Ethics (Declaration of Helsinki) for human studies..

\section{Statistical analysis:}

Data analysis was performed using the software SPSS (Statistical Package for the Social Sciences) version 20 (IBM corp.Released 2011.IBM SPSS statistics for windows, Version20.0.Armonk, NY: IBM Corp.). Quantitative variables were described using their means and standard deviations. Categorical variables were described using their absolute frequencies. To compare means of two groups, independent sample $t$ test test (used with normally distributed data) was used and to compare medians of two groups, Mann whitnet test (used with not normally distributed data) was used. Focusing on the differences in the levels of (TSH, FT4 and FT3) between the both groups of study. Also noticed the difference between clinical signs in both groups .P value that was $\leq 0.05$, considered statistically significant.

\section{Result:}

Forty eight patients were included in the study; they were classified into two groups, 24 patients with overt hyperthyroidism (group 1) and another 24 patients with subclinical hyperthyroidism (group 2). Table (1) illustrates the difference between the two groups as regard age, sex and BMI. Female predominance was significantly evident in group (1) patients than group (2) $(\mathrm{p}=0.008)$. Age also was 
significantly different between two groups, in the group (1) median age was 35 and the group (2) median age was $49(\mathrm{p}=0.001)$. On the contrary there was no Statistical significance ( $\mathrm{p}=0.137$ ) for BMI between two groups. Median BMI for group (1) was 29.9 and for group (2) median was 28.6.

Table (1) : Clinico-demographic data in overt hyperthyroid group(1) and subclinical hyperthyroid group (2):

\begin{tabular}{|c|c|c|c|c|c|c|c|}
\hline & \multicolumn{4}{|c|}{ Group } & \multirow[t]{3}{*}{ Test } & \multirow[t]{3}{*}{$\mathrm{P}$} \\
\hline & & \multicolumn{2}{|c|}{$\begin{array}{l}\text { Overt( group 1) } \\
\text { Hyperthyroidism }\end{array}$} & \multicolumn{2}{|c|}{$\begin{array}{l}\text { Subclinical (group } \\
\text { 2) Hyperthyroidism }\end{array}$} & & \\
\hline & & $\mathrm{N}$ & $\%$ & $\mathrm{~N}$ & $\%$ & & \\
\hline \multirow[t]{2}{*}{ Sex } & $\mathrm{F}$ & 22 & $91.7 \%$ & 14 & $58.3 \%$ & 7.1 & $* 0.008$ \\
\hline & $\mathrm{M}$ & 2 & $8.3 \%$ & 10 & $41.7 \%$ & & \\
\hline \multirow[t]{2}{*}{$\begin{array}{c}\text { Age } \\
\text { (years) }\end{array}$} & $\begin{array}{l}\text { Mean } \\
\pm \text { SD }\end{array}$ & \multicolumn{2}{|c|}{$37 \pm 12$} & \multicolumn{2}{|c|}{$50 \pm 10$} & -3.8 & $* *<0.001$ \\
\hline & Median & \multicolumn{2}{|c|}{$35(22-60$} & \multicolumn{2}{|c|}{$49(36-70$} & & \\
\hline \multirow[t]{2}{*}{$\begin{array}{c}\mathrm{BMI} \\
\mathrm{Kg} / \mathrm{m}^{2}\end{array}$} & $\begin{array}{l}\text { Mean } \\
\pm \text { SD }\end{array}$ & \multicolumn{2}{|c|}{$29.8 \pm 2.5$} & \multicolumn{2}{|c|}{$28.6 \pm 2.4$} & -1.5 & 0.137 \\
\hline & Median & \multicolumn{2}{|c|}{$29.9(25.5-33.6$} & \multicolumn{2}{|c|}{$28.6(24.8-32.4$} & & \\
\hline
\end{tabular}

All variables were compared using Independent T test except (*) Chi-square $\mathrm{X}^{2}$ test, (F) female, (M) male and (BMI) body mass index. ;[Continuous data are presented as median (range) or $\mathrm{n}(\%)]$.

As shown in table ( 2 ) all patients of group (1) had abnormal thyroid examination $54.2 \%$ of patients of group (1 ) had diffusely enlarged thyroid gland and the remaining $45.8 \%$ of them had nodular enlargement . On the contrary, 50 $\%$ of group (2) patients had showed no abnormalities, $41.7 \%$ with nodular enlargement and only $8.3 \%$ of them showed diffusely enlarged thyroid gland with highly significant difference between two groups $(\mathrm{p}=<0.001)$. As regard eye examination $50 \%$ of group (1) patients had eye abnormality on examination (33.3 $\%$ starring look and $16.7 \%$ with exophthalmos) and the other $50 \%$ showed no abnormality while $75 \%$ of group (2) patients showed no abnormality and only $25 \%$ 
of these patients had eye abnormality (16.7\% of them had starring look and $8,3 \%$ showed exophthalmos) .But, we noticed there was no significant difference between two groups in eye abnormalities $(\mathrm{p}=0.074)$.

Table ( 2 ): Clinical findings in overt hyperthyroid $\operatorname{group}(1)$ and subclinical hyperthyroid group (2): as regard neck examination for thyroid gland abnormality and presence or absence of eye abnormality (exophthalamos or starring look):

\begin{tabular}{|c|c|c|c|c|c|c|c|}
\hline & \multicolumn{4}{|c|}{ Group } & \multirow{3}{*}{$\begin{array}{c}\mathrm{X}^{2} \\
\text { Test }\end{array}$} & \multirow[t]{3}{*}{$\mathrm{P}$} \\
\hline & & \multicolumn{2}{|c|}{$\begin{array}{c}\text { Overt } \\
\text { Hyperthyroidism } \\
\text { (group 1 ) }\end{array}$} & \multicolumn{2}{|c|}{$\begin{array}{c}\text { Subclinical } \\
\text { Hyperthyroidism } \\
\text { (group 2 ) }\end{array}$} & & \\
\hline & & $\mathrm{N}$ & $\%$ & $\mathrm{~N}$ & $\%$ & & \\
\hline \multirow[t]{3}{*}{ Neck Exam } & No abnormality & 0 & $0.0 \%$ & 12 & $50.0 \%$ & \multirow[t]{3}{*}{20.1} & \multirow[t]{3}{*}{$*<0.001$} \\
\hline & Diffuse Enlarg. & 13 & $54.2 \%$ & & 2 & & \\
\hline & Nodular Enlarg. & 11 & $45.8 \%$ & & 10 & & \\
\hline \multirow[t]{3}{*}{ Eye Exam. } & Exophthalmos & 4 & $16.7 \%$ & 2 & $8.3 \%$ & 3.2 & 0.202 \\
\hline & Starring & 8 & $33.3 \%$ & 4 & $16.7 \%$ & & \\
\hline & $\mathrm{N}$ & 12 & $50.0 \%$ & 18 & $75.0 \%$ & & \\
\hline
\end{tabular}

Table (3) showing $83.3 \%$ of patients of group (1) had high thyroid uptake and only $16.6 \%$ with normal uptake.On the other hand $62.5 \%$ of patients of group (2) had showed high thyroid uptake and $37.5 \%$ with normal uptake by thyroid gland . But, there was no significant difference between the two groups $(\mathrm{p}=0.108)$. 
Table (3) : Thyroid Scan findings in overt hyperthyroid group(1) and subclinical hyperthyroid group (2):

\begin{tabular}{|c|c|c|c|c|c|c|c|}
\hline & & \multicolumn{4}{|c|}{ Group } & \multirow{3}{*}{$\begin{array}{c}\mathrm{X}^{2} \\
\text { Test }\end{array}$} & \multirow[t]{3}{*}{$\mathrm{P}$} \\
\hline & & \multicolumn{2}{|c|}{$\begin{array}{c}\text { Overt } \\
\text { Hyperthyroidism } \\
\text { (group 1) }\end{array}$} & \multicolumn{2}{|c|}{$\begin{array}{c}\text { Subclinical } \\
\text { Hyperthyroidism } \\
\text { (group 2) }\end{array}$} & & \\
\hline & & $\mathrm{N}$ & $\%$ & $\mathrm{~N}$ & $\%$ & & \\
\hline \multirow{2}{*}{$\begin{array}{c}\text { Thyroid } \\
\text { Scan }\end{array}$} & High Uptake & 20 & $83.3 \%$ & 15 & $62.5 \%$ & \multirow[t]{2}{*}{2.6} & \multirow[t]{2}{*}{0.108} \\
\hline & Normal uptake & 4 & $16.6 \%$ & 9 & $37.5 \%$ & & \\
\hline
\end{tabular}

Table (4) showed that in group (1)patients the median TSH level was 0.02 ,median for F.T4 level was 26.09 and F.T3 median level 8.32 . In group( 2 ) patients TSH median was 0.04 ,F.T4 median was 21.0 and F.T3 median was 5.75 .We noticed that there was a highly statistical significant variation between the two groups as regard F. T4 $(\mathrm{P}=<0.001)$ and also $\mathrm{F} . \mathrm{T} 3(\mathrm{p}=$ $<0.001)$, but no significant difference in $\operatorname{TSH}(\mathrm{p}=0.223)$. 
Table (4) : Thyroid profile in both groups ( markers for thyroid function :(TSHm - F.

T4- F. T3 ) :

\begin{tabular}{|c|c|c|c|c|c|c|c|c|}
\hline & \multicolumn{4}{|c|}{ Group } & \multirow{2}{*}{\multicolumn{2}{|c|}{ Total }} & \multirow{3}{*}{$\begin{array}{c}\text { MW- } \\
\text { test }\end{array}$} & \multirow[t]{3}{*}{$\mathrm{P}$} \\
\hline & \multicolumn{2}{|c|}{$\begin{array}{c}\text { Overt } \\
\text { Hyperthyroidism } \\
\text { (Group 1) }\end{array}$} & \multicolumn{2}{|c|}{$\begin{array}{c}\text { Subclinical } \\
\text { Hyperthyroidism } \\
\text { (Group 2) }\end{array}$} & & & & \\
\hline & Median & Range & Median & Range & Median & Range & & \\
\hline $\begin{array}{c}\text { TSH } \\
\mu \mathrm{IU} / \mathrm{mL} .\end{array}$ & 0.02 & $0.01-0.08$ & 0.04 & $0.01-0.12$ & 0.03 & $0.01-0.12$ & -1.2 & 0.223 \\
\hline $\begin{array}{l}\text { F.T } 4 \\
\text { (pmol//) }\end{array}$ & 26.09 & $\begin{array}{c}22.00- \\
35.81\end{array}$ & 21.00 & $\begin{array}{l}18.00- \\
23.70\end{array}$ & 23.00 & $\begin{array}{c}18.00- \\
35.81\end{array}$ & -5.4 & $* * 0.001$ \\
\hline $\begin{array}{l}\text { F.T3 } \\
\text { (pmol// }\end{array}$ & 8.32 & $6.90-12.00$ & 5.75 & $3.60-7.00$ & 7.00 & $3.60-12.00$ & -5.8 & $* *<0.001$ \\
\hline
\end{tabular}

TSH ( thyroid stimulating hormone ), F.T4 (free throid hormone T4 ) , F .T3 (free thyroid *

${ }^{*} \mathrm{p} \leq 0.001$ is statistically highly significant

This table (5) shows that most of the cases of overt hyperthyroidism group (1)were Grave's disease (50.0\%) while $33.3 \%$ diagnosed with multinodular goiter and only $16.7 \%$ had toxic adenoma . In subclinical hyperthyroidism group (2) patients ,Grave's disease also was the commonest cause in the cases of group (2) $25 \%$.Then come cases with multinodular goiter (16.7\%) and only $8.3 \%$ of group (2)patients with toxic adenoma . 
Table (5) causes of thyroid dysfunction :

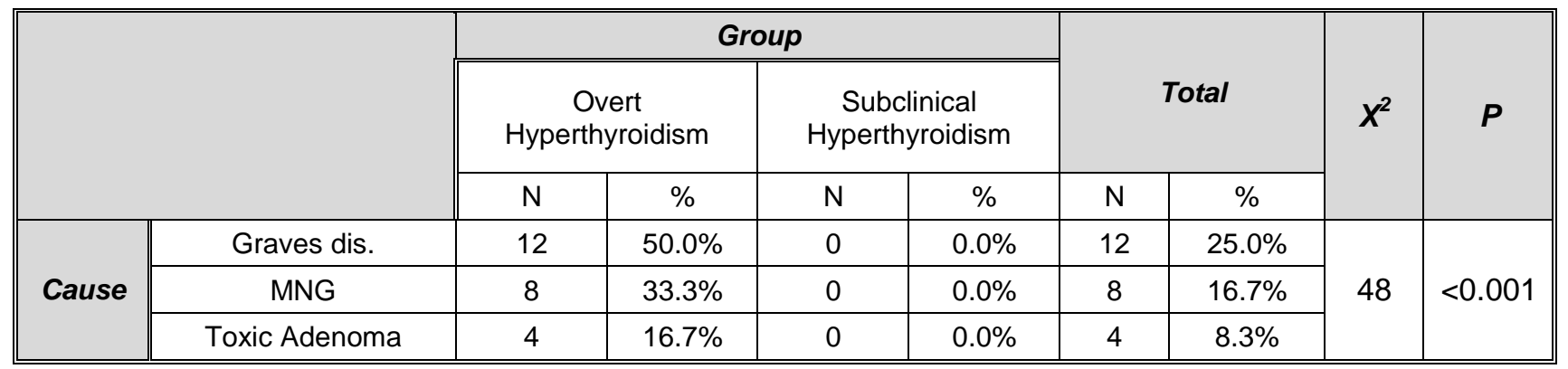

Table (6) As regard clinical status at time of examination $79.2 \%$ of group (1) patients were complaining of signs and symptoms of hyperthyroidism, and only $20.8 \%$ of them were improved .While in group (2) $66.7 \%$ of patients were asymptomatic and the other $33.3 \%$ were symptomatic with Statistical significance between the two groups $(\mathrm{p}=0.001)$

Table ( 6 ) : Clinical status in both groups :

\begin{tabular}{|c|c|c|c|c|c|c|c|}
\hline & \multicolumn{4}{|c|}{ Group } & \multirow{3}{*}{$\begin{array}{c}\mathrm{X}^{2} \\
\text { Test }\end{array}$} & \multirow[t]{3}{*}{$\mathrm{P}$} \\
\hline & & \multicolumn{2}{|c|}{$\begin{array}{c}\text { Overt } \\
\text { Hyperthyroidism } \\
\text { Group (1) }\end{array}$} & \multicolumn{2}{|c|}{$\begin{array}{c}\text { Subclinical } \\
\text { Hyperthyroidism } \\
\text { Group (2) } \\
\end{array}$} & & \\
\hline & & $\mathrm{N}$ & $\%$ & $\mathrm{~N}$ & $\%$ & & \\
\hline \multirow{2}{*}{$\begin{array}{c}\text { Clinical } \\
\text { status }\end{array}$} & asymptomatic & 5 & $20.8 \%$ & 16 & $66.7 \%$ & 10.2 & $* * 0.001$ \\
\hline & Symptomatic & 19 & $79.2 \%$ & 8 & $33.3 \%$ & & \\
\hline
\end{tabular}

$* * \mathrm{p} \leq 0.001$ is statistically highly significant

\section{Discussion:}

Undiagnosed and untreated hyperthyroidism causes major clinical problems, with negative patient outcomes and rising health-care expenses. As a result, proper diagnosis, classification, careful therapy, and clinical response monitoring of hyperthyroid patients are critical. ${ }^{[6]}$ 
Subclinical hyperthyroidism is a less common condition. The reported prevalence in adult populations is between $0.2 \%$ to $9.7 \%$, generally about $2 \%$ to $3 \%$. It is also more common in women and the elderly. ${ }^{[7]}$

So, we shed the light at this study on the value of clinical and biochemical identification of category of hyperthyroidism and correlation with thyroid gland scaninig for better management of hyperthyroidism.

Among the 48 patients included in this study $36 / 48 \quad(75 \%)$ were females and $12 / 48(25 \%)$ were males with a ratio of [3: 1]. This female predominance in our cases comes in agreement with results of Ertugrul study in which females $83 \%$ and the males $17 \%{ }^{[8]}$.

The median age for all patients in our study was around 41 years old. This comes in agreement with Ertugrul study in which median age was 43.6 years. ${ }^{[8]}$

Majority of the patients of study were overweight, the median BMI 29.2. On the contrary Ertugrul and Arikan studies documented that most of hyperthyroid patients had average body weight ( BMI $24 \cdot 7 \pm 5 \cdot 8) .^{[8,9]}$

In the current study, grave's disease was the commonest cause of hyperthyroid state then multinodular goiter and a small proportion with toxic nodule. There was no significant difference between the two groups of study as regard the cause.As regard thyroid scan evaluation We reported that $83.3 \%$ of all group (1) cases had high thyroid uptake, In group (2) patients $62 \%$ had high uptake, This comes in agreement with Arikan,Surks and Alswa studies whom also supported that most common causes of both types of hyperthyroidism was graves' disease $[9,10,11]$

We reported that most of the patients of overt hyperthyroidism (79\%) were symptomatic, all of them had abnormal thyroid examination and 50\% had thyroid eye disease .On the contrary most of subclinical hyperthyroidism (66.7\%)cases were asymptomatic ,50\% of them presented with abnormalities in thyroid examination and only $34 \%$ with thyroid eye disease .This comes in 
agreement with Surks study who noticed that patients with subclinical hyperthyroidism had minor clinical symptoms and signs than overt hyperthyroid. ${ }^{[10]}$

We reported that there was highly statistical significant variation between the two groups as regard F. T4 $(\mathrm{P}=<0.001)$ and also F .T3 $(\mathrm{p}=<0.001)$, but no significant difference in $\mathrm{TSH}(\mathrm{p}=0.223)$.TSH was below reference range in both groups but free T4and free T3 were increased only in group (1) overt hyperthyroid patients .this comes in accordance with Surks study results ${ }^{[10]}$

\section{Conclusion:}

In view of the present study we can conclude: Hyperthyroidism is highly prevalent in females than males. Overt hyperthyroid patients had more symptoms and signs than subclinical hyperthyroidism. Thyroid scan had an important role in determination of the cause of hyperthyroidism

. Funding: Not applicable.

Availability of data and materials: All analyzed and generated data through this study are incorporated in this published article.

\section{Consent for publication}

An informed written consent had been taken from all participating patients to publish their data.

Competing interests: The authors announce that having no compete 


\section{REFERANCES}

1) Bahn RS, Burch HB, Cooper DS, Garber JR, Greenlee MC, Klein I, et al. Hyperthyroidism and other causes of thyrotoxicosis: management guidelines of the American Thyroid Association and American Association of Clinical Endocrinologists. Endocr Pract. 2011 May-Jun;17(3):456-520. doi: 10.4158/ep.17.3.456.

2) Simone De Leo Sun Y Lee, and Lewis E Braverman final edited form as: Lancet. 2016 Aug 27; 388(10047): 906-918.

3) Goichot Schwartz F, Bergmann N, Zerahn B, Faber J. Incidence rate of symptomatic painless thyroiditis presenting with thyrotoxicosis in Denmark as evaluated by consecutive thyroid scintigraphies. Scand J Clin Lab Invest. 2013;73:240-44DOI:10.1111/cen.12816.

4) Vaidya B, Pearce SH. Diagnosis and management of thyrotoxicosis . BMJ. 2014;349:g5128.

5) Giovanella L, Avram AM, Iakovou I, Kwak J, Lawson SA, et al. EANM practice guideline/SNMMI procedure standard for RAIU and thyroid scintigraphy. Eur J Nuclear Med Mol Imag. 2019;46(12):2514-25.

6) Taylor, Peter N., Albrecht, Diana, Scholz, Anna, Gutierrez-Buey, Gala, Lazar etal,. 2018. Global epidemiology of hyperthyroidism and hypothyroidism. Nature Reviews Endocrinology 14 (5) , pp. 301-316. 10.1038/nrendo.2018.1.

7) Ye An Kim and Young Joo Park Published online 2014 Mar 14. doi: 10.3803/EnM.2014.29.1.20 Prevalence and Risk Factors of Subclinical Thyroid Disease . 
8) Ertugrul DT, Yavuz B, Ata N, Yalcin AA, Kucukazman M, Algul B, Dal $\mathrm{K}$, et al. Decreasing brain natriuretic peptide levels after treatment for hyperthyroidism. Endocr. J. - January 1, 2009; 56 (9); 1043-8.

9) Arikan S, Tuzcu A, Gokalp D, Bahceci M, Danis R. Hyperthyroidism may affect serum $\mathrm{N}$-terminal pro-B-type natriuretic peptide levels independently of cardiac dysfunction. - Clin. Endocrinol. (Oxf). 2007; 67 (2); 202.8

10) Surks MI, Ortiz E, Daniels GH, Sawin CT, Col NF, Cobin RH, Subclinical thyroid disease: scientific review and guidelines for diagnosis and management. JAMA. 2004 Jan 14;291(2):228-38. doi: 10.1001/jama.291.2.228. PMID: 14722150.

11) Alswat, K., Assiri, S.A., Althaqafi, R.M.M. et al. Scintigraphy evaluation of hyperthyroidism and its correlation with clinical and biochemical profiles. BMC Res Notes 13, 324 (2020). https://doi.org/10.1186/s13104-020-05164-5 